\title{
Phenotypic comparison between rhizosphere and clinical isolates of Burkholderia cepacia
}

\author{
Annamaria Bevivino, ${ }^{1}$ Silvia Tabacchioni, ${ }^{1}$ Luigi Chiarini, ${ }^{1}$ \\ M. Vittoria Carusi, ${ }^{1}$ Maddalena Del Gallo ${ }^{2}$ and Paolo Visca ${ }^{3}$
}

Author for correspondence: Annamaria Bevivino. Tel: +3963048 3868. Fax: +39630484808 .

1 ENEA (Italian National Agency for New Technologies, Energy and Environment) CRE Casaccia, Biotechnology and Agriculture Sector, Technological Innovation Department, via Anguillarese 301, $00060 \mathrm{~S}$. Maria di Galeria, Roma, Italy

2 Department of Food Technology, Environmental and Microbiological Sciences, University of Molise, $\mathbf{8 6 1 0 0}$ Campobasso, Italy

3 Microbiology Institute, University of Rome 'La Sapienza', 00100 Roma, Italy

\begin{abstract}
The phenotypic characteristics of four Burkholderia cepacia strains isolated from the rhizosphere and the clinical environment were compared. Tests included optimum growth temperature, utilization of carbon sources, production of HCN, indole-3-acetic acid (IAA) and siderophores, proteolytic activity, nitrogen fixation, inhibition of some phytopathogenic fungi, adherence to human mucosal and plant root epithelia, and greenhouse-based plant-growth promotion experiments using cucumber (Cucumis sativus). Results indicated that the strains of $B$. cepacia isolated from the rhizosphere differ markedly from their clinical counterparts. Strains isolated from the rhizosphere grew over a wider temperature range, fixed nitrogen and produced IAA, did not produce proteases, displayed a wider antibiosis against the phytopathogenic fungi studied, did not adhere to human uroepithelial cells, promoted growth of $C$. sativus and only produced a hydroxamate-like siderophore. In contrast, clinical isolates could not fix nitrogen or produce IAA, produced proteases, adhered to human uroepithelial cells, did not promote the growth of $C$. sativus and, in addition to a hydroxamate-like siderophore, produced pyochelin and salicylate siderophores. All four isolates exhibited the ability to adhere to the root tissue of $C$. sativus and were unable to produce HCN.
\end{abstract}

Keywords: Burkbolderia (Pseudomonas) cepacia, phenotype, siderophores, pathogenicity, adherence

\section{INTRODUCTION}

Burkbolderia cepacia (basonym Pseudomonas cepacia), formerly included in the rRNA homology group II of the genus Pseudomonas (Palleroni, 1984), is now recognized as the type species of the new genus Burkholderia on the basis of cellular lipid and fatty acid composition, 16S rRNA sequences, DNA-DNA homology values, and phenotypic characteristics (Yabuuchi et al., 1992). Although originally described as the causal agent of soft rot of onions (Burkholder, 1950), B. cepacia has later been reported to be a widely spread species in different soil and root samples (Hebbar et al., 1992a). In recent years, there has been considerable interest in using $B$. cepacia as a biocontrol agent because of its ability to antagonize and repress soilborne plant pathogens (Homma et al., 1990; Hebbar et al., 1992a, b, c; McLoughlin et al., 1992). Some biotypes of $B$. cepacia have been implicated in biodegradation of pesticides (Folsom et al., 1990; Kilbane $e t$ al., 1983). Occurrence and distribution of B. cepacia are not confined solely to environmental sources. This species has also been isolated from clinical specimens of human origin, particularly from cystic fibrosis patients (Goldmann \& Klinger, 1986), as well as from contaminated medical devices and solutions employed in hospital practice (Gilardi, 1983). B. cepacia is characterized by an extreme resistance to antimicrobial agents (Gilardi, 1971), and by the ability to grow in minimal media including purified water systems (Carson et al., 1973). These factors have led to the emergence of $B$. cepacia as a serious problem in health care product contamination (Craven $e t$ al., 1981), nosocomial infections (Martone et al., 1987), and recalcitrant infections of cystic fibrosis patients (Isles et al., 1984; McKevitt \& Woods, 1984; Thomassen et al., 1985).

Strains of $B$. cepacia isolated from plant, soil and human samples have previously been distinguished according to differences in bacteriocin production, maceration of onion slices, hydrolysis of low pectate agar and the size of resident plasmids (Gonzalez \& Vidaver, 1979). Lennon \& DeCicco (1991) compared strains of B. cepacia from 
clinical, pharmaceutical-industrial, and environmental origin for the presence of plasmid DNA. In contrast to the environmental group, the clinical isolates varied considerably in the number and size of harboured plasmids which were cryptic and unrelated to the source of strains. The aim of the present study was to compare B. cepacia strains of clinical and rhizosphere origin for characters relevant to virulence in the human host as well as factors involved in biological control and plant-growth promotion. This will enable the selection of strains that may be used safely and effectively as biocontrol agents.

\section{METHODS}

Microbial cultures. The different B. cepacia strains used in this study were: B. cepacia PHP7 and TVV75, isolated in France and Vietnam from the rhizosphere of maize and rice, respectively (obtained from T. Heulin and Tran Van Van, Centre Pedologie Biologique, CNRS, Nancy, France), and the clinical isolates $7 / 25$ and $9 / 27$, isolated, respectively, from urine and sputum of two patients with cystic fibrosis from the University Hospital 'Policlinico Umberto I' (Rome, Italy). All the strains were identified with the API 20NE (Bio-Mérieux) system. Pseudomonas aeruginosa PAO1 (ATCC15692) was obtained from the American Type Culture Collection (Rockville, MD, USA).

Fungal cultures of Fusarium culmorum ISPAVE F125, F. moniliforme ISPAVE F44, F. oxysporum ISPAVE F45 and F. graminearum ISPAVE F202 were kindly provided by L. Corazza, Phytopathology Institute, MAF, Rome, Italy. The plantpathogenic fungi $F$. solani EF5 and Rbizoctonia solani EF9 were obtained from the Plant Pathology Institute, University of Naples, Italy. Fungi were maintained on potato dextrose agar (PDA, Difco) with monthly transfers.

Glassware preparation. For experiments requiring low-iron $[\mathrm{Fe}(\mathrm{III})]$ conditions, the glassware was rendered $\mathrm{Fe}(\mathrm{III})$-free by $24 \mathrm{~h}$ treatment with $6 \mathrm{M} \mathrm{HCl}$, rinsed once in distilled water and finally rinsed in deionized water from a Milli $Q$ system (Millipore) before sterilization. This high quality deionized water was also used in all growth media and in the preparation of all solutions.

Effect of temperature on growth rates and utilization of carbon sources. For growth rate determinations, cultures of $B$. cepacia strains were grown in M9 (Guterman, 1973) with glucose $\left(10 \mathrm{~g} \mathrm{l}^{-1}\right)$ as the carbon source. Cultures were incubated at $21{ }^{\circ} \mathrm{C}, 28^{\circ} \mathrm{C}, 37^{\circ} \mathrm{C}$ and $42^{\circ} \mathrm{C}$, with rotary shaking at 200 r.p.m. in a Kühner Clim-O-Shake, model ISF-1-V. Growth was monitored by measuring optical density at $620 \mathrm{~nm}$ at $1 \mathrm{~h}$ intervals.

Carbon source utilization assays were performed by adding $20 \mathrm{mM}$ organic substrates to the M9 basal salt solution.

Siderophore synthesis. Siderophore production was preliminarily detected using chrome azurol-S (CAS) plates as described by Schwyn \& Neilands (1987). The CAS assay is a universal assay for $\mathrm{Fe}$ (III)-chelators and allows detection of siderophores independently of their structure. The presence of a $\mathrm{Fe}$ (III)-chelator is indicated by the colour change of a blue$\mathrm{Fe}$ (III)-CAS complex, resulting in a yellow-gold halo around colonies growing on CAS agar plates.

Siderophore production was also tested in culture supernatants by means of specific colorimetric tests. Cultures of $B$. cepacia were grown for about $48 \mathrm{~h}$ at $37^{\circ} \mathrm{C}$ and 150 r.p.m. either in DCAA (Visca et al., 1992b) or in SM9 (Visca et al., 1992c) media. Removal of trace amounts of $\mathrm{Fe}$ (III) was achieved by treatment with Chelex-100 resin (Bio-Rad). The activated resin was added to the medium at $5 \mathrm{~g} \mathrm{l}^{-1}$, stirred at $4{ }^{\circ} \mathrm{C}$ for $20 \mathrm{~h}$, and removed by filtration through Whatman no. 4 filter paper (Clifton). Hydroxamate-like siderophores were detected using the test of Csàky (1948), with hydroxylamine hydrochloride as the standard. Catechol-type siderophores were measured using the test developed by Annow (1937), with 2,3-dihydroxybenzoic acid as the standard. Pyochelin, cepabactin and salicylic acid were extracted and visualized as previously described by Cox \& Graham (1979), Meyer et al. (1989) and Visca et al. (1993), respectively. For pyochelin and salicylic acid detection, supernatants from cultures grown in DCAA were adjusted to $\mathrm{pH} 2 \cdot 0$ with $\mathrm{HCl}$, extracted twice with 0.4 vols ethyl acetate and concentrated by rotary evaporation. For cepabactin determination, supernatants from cultures in succinate mineral medium

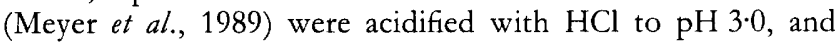
extracted twice with 0.2 vols chloroform. The chloroform extracts were washed twice with water, filtered on anhydrous sodium sulphate, and evaporated under vacuum to dryness. The dry residues obtained by both procedures were dissolved in a small volume of methanol and applied to a silica gel $G$ thin layer chromatography plate (TLC), using chloroform/acetic acid/ ethanol $(90: 5: 2 \cdot 5$, by vol.) as the development solvent. Siderophores were characterized by chromatographic mobility $\left(R_{F}\right)$, fluorescence emission, and chemical reactivity when sprayed with $0 \cdot 1 \mathrm{M} \mathrm{FeCl}_{3}$ in $0 \cdot 1 \mathrm{M} \mathrm{HCl}$ or with the ammoniacal silver nitrate reagent for thiazolidine rings (Visca et al., 1992c, 1993).

Indole-3-acetic acid (IAA) production. B. cepacia strains were grown for $48 \mathrm{~h}$ in SM9 supplemented with $100 \mu \mathrm{g}$ of $\mathrm{L}$ tryptophan $\mathrm{ml}^{-1}$ and $100 \mu \mathrm{M} \mathrm{FeCl}_{3}$. The supernatant was recovered by cell centrifugation for $20 \mathrm{~min}$ at $5500 \mathrm{~g}$, adjusted to $\mathrm{pH} 2 \cdot 5$, and applied to a C-18 Sep-Pak cartridge (Sagee $e t$ al., 1986). The cartridge was washed with distilled water and IAA was eluted with methanol containing $10 \mu \mathrm{g}$ butylated hydroxytoluene $\mathrm{ml}^{-1}$, as described by Forni et al. (1992). The eluate containing IAA was evaporated under vacuum to dryness and dissolved in $200 \mu \mathrm{l}$ methanol. IAA was determined using the Salkowski reagent (Ehmann, 1977).

Cyanide production. Cyanogenesis was detected according to Castric \& Castric (1983), using HCN-sensitive Whatman 3MM paper disks soaked in the HCN detection reagent of Feigl \& Anger (1966). P. aeruginosa PAO1 was used as the cyanogenic control.

Protease activity. Protease activity was first qualitatively assayed in the API 20NE test. Quantitative determinations were made on supernatants of $30 \mathrm{~h}$ cultures in SM9 using the colorimetric assay described by Tomarelli et al. (1949), with azoalbumin as the substrate. One unit of proteolytic activity was defined as the amount of enzyme hydrolysing $1 \mu \mathrm{g}$ of azoalbumin in $1 \mathrm{~min}$ at $37^{\circ} \mathrm{C}$ and was calculated assuming a $A_{440}^{1 \%}$ for azoalbumin of 34 .

$\mathbf{N}_{\mathbf{2}}$ fixation. Nitrogenase activity was determined by monitoring the reduction of acetylene to ethylene by gas chromatography (Hardy et al., 1973; Lifshitz et al., 1986). Bacterial cultures were grown in $125 \mathrm{ml}$ stoppered flasks containing $15 \mathrm{ml}$ of the following medium $\left(\mathrm{g} \mathrm{l}^{-1}\right): 1.0 \mathrm{KH}_{2} \mathrm{PO}_{4}, 1.74 \mathrm{~K}_{2} \mathrm{HPO}_{4}$, $0 \cdot 2 \mathrm{MgSO}_{4}, 0 \cdot 1 \mathrm{NaCl}, 0.02 \mathrm{CaCl}_{2}, 0.015 \mathrm{FeCl}_{3}, 0.002 \mathrm{NaMoO}_{4}$, $0 \cdot 08$ yeast extract (Difco), 5.0 glucose, $\mathrm{pH} 7 \cdot 0$. Cultures were grown on a rotary shaker $\left(150\right.$ r.p.m.) at $28{ }^{\circ} \mathrm{C}$ for $24 \mathrm{~h}$, under an atmosphere of $99.9 \%(\mathrm{v} / \mathrm{v}) \mathrm{N}_{2}$ and $0.1 \% \mathrm{O}_{2}$, and cells were collected by centrifugation $\left(10000 \mathrm{~g}, 4^{\circ} \mathrm{C}, 20 \mathrm{~min}\right)$. The pellets were washed twice with the same medium and $100 \mu \mathrm{l}$ aliquots were transferred to $15 \mathrm{ml}$ of fresh medium to give an initial concentration of approximately $5.5 \times 10^{5}$ c.f.u. $\mathrm{ml}^{-1}$. Following an additional $4 \mathrm{~h}$ incubation, $10 \%$ of the volume of the 
atmosphere of each flask was replaced with acetylene, and the incubation was continued for an additional $48 \mathrm{~h}$ under the same conditions. The ethylene concentration in the flasks was assayed by means of a gas chromatograph (model 8410, Perkin-Elmer) equipped with a flame ionization detector and a Porapak $\mathrm{N}$ $80 / 100$ mesh column [ $1 \mathrm{~m}$ by $0 \cdot 125 \mathrm{in}$. (ca. $3 \cdot 2 \mathrm{~mm}$ )]. Aliquots of $250 \mu$ l were used for the assay. The operating conditions of the gas chromatograph were as follows: oven temperature, $90^{\circ} \mathrm{C}$; injection-detector temperature, $190^{\circ} \mathrm{C}$; carrier gas,

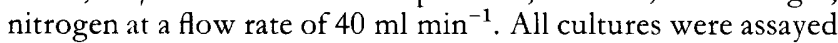
in triplicate and compared with a standard ethylene curve.

Screening for in vitro antibiosis. An in vitro assay was performed to test the ability of $B$. cepacia strains to suppress fungal phytopathogens on PDA and King's B (KB) (King et al., 1954) media. An agar plug with mycelium was placed at the centre of the agar plate and bacterial strains were streaked near the edge of the petri dish at fixed positions. Plates were incubated at $28^{\circ} \mathrm{C}$, and the growth of fungal phytopathogens was measured at $48 \mathrm{~h}$ intervals. The percentage inhibition of the fungal growth was calculated with the following formula: $\left[\left(R_{1}-R_{2}\right) / R_{1}\right] \times 100$, where $R_{1}$ is the farthest radial distance grown by the fungus in the direction of the antagonist (a control value), and $R_{2}$ is the distance grown on a line between the inoculation positions of the fungal phytopathogen and the antagonist strain of B. cepacia (Whipps, 1987).

Adherence to human uroepithelial cells. The adherence assay was performed with P-phenotype uroepithelial cells collected by centrifugation $\left(2000 \mathrm{~g}, 10 \mathrm{~min}, 4^{\circ} \mathrm{C}\right)$ from fresh morning urine of a single female healthy donor and washed three times in phosphate buffered saline (PBS, Flow Laboratories), pH 7·2. The number of epithelial cells per $\mathrm{ml}$ was calculated by counting in a Burker haemocytometer and adjusted to a concentration of about $2 \times 10^{5}$ cells $\mathrm{ml}^{-1}$ with PBS. The adherence of $B$. cepacia to uroepithelial cells was examined by mixing together $0.5 \mathrm{ml}$ samples of a standard bacterial suspension in PBS $\left(10^{8}\right.$ c.f.u. $\left.\mathrm{ml}^{-1}\right)$ and $0.5 \mathrm{ml}$ of epithelial cells $\left(10^{5}\right.$ cells $\left.\mathrm{ml}^{-1}\right)$ in a water bath for $45 \mathrm{~min}$ at $37^{\circ} \mathrm{C}$. Cells were separated from unattached bacteria by continuous vacuum washing with PBS through $8 \mu \mathrm{m}$ Nucleopore filters. The filter membranes were gently pressed against glass slides which had previously been coated with a thin albumin layer. Slides were fixed in absolute methanol and stained with Giemsa. The total adherent bacteria per epithelial cell were microscopically determined. In each experiment, 40 epithelial cells were examined and duplicate determinations were performed. Strains showing 30 or more attached bacteria per epithelial cell were classified as adhesive (Visca et al., 1992a). Whenever this procedure was used, control epithelial cell preparations without exogenous bacteria were treated in the above manner to detect any indigenous organism which may have been present.

Seed sterilization. Commercial cucumber seeds (Cucumis sativus L. cv. Marketmore) were obtained from Four s.r.l. (Bolzano, Italy). Surface sterilization was obtained as follows: seeds were submerged for $2 \mathrm{~min}$ in $95 \%$ (v/v) ethanol, rinsed five times with sterile distilled water, treated with $0.56 \% \mathrm{H}_{2} \mathrm{O}_{2}$ for $16 \mathrm{~h}$, and finally washed three times with sterile distilled water. Surface-sterilized seeds were germinated aseptically in the dark on nutrient agar (NA, Difco) plates for $48 \mathrm{~h}$ at $25^{\circ} \mathrm{C}$, to check for the presence of contaminating micro-organisms.

Adherence studies to $\boldsymbol{C}$. sativus roots. Seedlings were transferred onto Petri dishes containing a filter paper soaked with sterile distilled water. After $3 \mathrm{~d}$ of growth in a controlled environment growth chamber at $25{ }^{\circ} \mathrm{C}$ with a $16 / 8 \mathrm{~h}$ light/dark cycle and $80 \%$ relative humidity, the roots were used in the attachment assay. The assay system consisted of a glass tube
$(160 \times 22 \mathrm{~mm}$ diam.) filled with $50 \mathrm{~g}$ of a sandy soil--vermiculite mixture $(3: 1, \mathrm{v} / \mathrm{v})$ saturated with $10 \mathrm{ml}$ of water. This mixture was used to facilitate soil removal from the roots of seedlings and minimize root damage. The tubes were sterilized by autoclaving at $127^{\circ} \mathrm{C}$ for $30 \mathrm{~min}$ on two consecutive days. One seedling was transferred to each tube, and inoculated with $10^{6}$ B. cepacia cells which had been grown in $\mathrm{KB}$ for $24 \mathrm{~h}$ at $28^{\circ} \mathrm{C}$ on a gyratory shaker $(150$ r.p.m.). The tubes were capped and incubated in a growth chamber at a constant temperature of $25^{\circ} \mathrm{C}$, with a $16 / 8 \mathrm{~h}$ light/dark cycle, and an average light intensity of $340 \mu \mathrm{E} \mathrm{m}^{-2} \mathrm{~s}^{-1}$. After 1 week, the seedlings were aseptically removed from the tubes, and each root was sequentially immersed into a series of $50 \mathrm{ml}$ tubes containing $25 \mathrm{ml}$ PBS, pH 6.0. Samples $(0 \cdot 1 \mathrm{ml})$ of each washing step were appropriately diluted and plated on NA. Bacterial colonies were counted after $24 \mathrm{~h}$ incubation at $28^{\circ} \mathrm{C}$. After the last PBS wash, the roots were excised with sterile forceps, crushed in a sterile mortar, and the number of bacteria was determined by plate counts on NA. To study bacterial penetration into the root, the seedlings were inoculated as described above, and after one week of growth were removed from the tubes. To kill attached bacteria, roots were immersed in $3 \%(\mathrm{w} / \mathrm{v})$ calcium hypochlorite for $3 \mathrm{~min}$, washed thoroughly in sterile distilled water, and crushed in a sterile mortar. The number of bacteria was estimated as above.

Pot experiments. Three-day-old $C$. sativus sterile seedlings were transferred aseptically to sterile 31 pots with a diameter of $20 \mathrm{~cm}$ (4 seeds per pot), and inoculated with $10^{6}$ viable cells of B. cepacia grown to the late exponential phase in SM9. The soil utilized was an alkaline $\mathrm{Fe}$ (III)-poor substrate consisting of a mixture of calcareous soil and sand (3:1, w/w), pH 8.8, containing $0.07 \%$ nitrogen, $63 \%$ calcium, $0.47 \%$ potassium, traces of phosphorus, no carbon, no assimilable iron. To study the plant-growth-promoting activity of B. cepacia strains in the absence of competing microflora, the soil was sterilized by autoclaving twice at $127^{\circ} \mathrm{C}$ for $30 \mathrm{~min}$. Greenhouse treatments were as follows: (i) uninoculated controls, (ii) inoculated with B. cepacia PHP7, (iii) inoculated with B. cepacia TVV75, (iv) inoculated with B. cepacia $7 / 25$, (v) inoculated with B. cepacia $9 / 27$. Pots were watered twice a week alternately with $250 \mathrm{ml}$ of sterile deionized water, and $250 \mathrm{ml}$ of mineral solution (Mitchell \& Livingstone, 1968) for a total of 10 applications. The plants were grown in a greenhouse at $25^{\circ} \mathrm{C}$ during the day and $16^{\circ} \mathrm{C}$ at night with a $16 / 8 \mathrm{~h}$ light/dark period. Each treatment was replicated 16 times and plants were harvested $40 \mathrm{~d}$ after germination. The root and shoot tissues of each plant were dried at $85^{\circ} \mathrm{C}$ for $24 \mathrm{~h}$ and weighed. Data were analysed using Duncan's Multiple-Range Test.

\section{RESULTS}

\section{Parameters influencing the growth of $B$. cepacia strains}

To study the carbon source utilization profile of B. cepacia strains a number of carbon sources released by the roots of plants (Rovira, 1965) were added to the M9 basal salt solution at a final concentration of $20 \mathrm{mM}$. All the strains were able to utilize succinic acid, malic acid, citric acid, sucrose, xylose, arabinose, cellobiose, mannose, mannitol, adipate, caprate, phenylacetate, lactose, galactose, glucose, gluconate, $N$-acetyl-D-glucosamine, leucine, asparagine, glutamic acid, aspartic acid, proline, arginine, but did not grow on oxalic acid and maltose as the sole carbon source. Lysine utilization was shown for clinical strains only. 


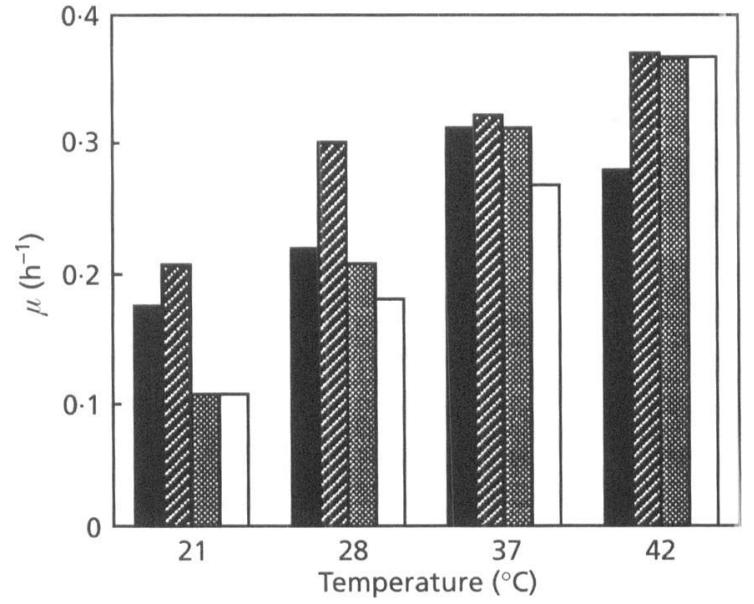

Fig. 1. Effect of temperature on growth rates $(\mu)$ of $B$. cepacia strains. —, PHP7; $\square, T V V 75 ;$ 7/25; $\square, 9 / 27$.

The growth rates of the $B$. cepacia isolates at temperatures ranging from $21{ }^{\circ} \mathrm{C}$ to $42{ }^{\circ} \mathrm{C}$ were also determined. Fig. 1 shows that the two clinical isolates of $B$. cepacia display maximum growth at $42{ }^{\circ} \mathrm{C}$, whereas rhizosphere strains gave different responses to increasing temperatures. The highest growth rate of B. cepacia PHP7 was at $37^{\circ} \mathrm{C}$, whereas for $B$. cepacia TVV75 the maximum growth rate was observed at $42{ }^{\circ} \mathrm{C}$. It is worth noting that the growth rates at $21{ }^{\circ} \mathrm{C}$ were significantly higher for rhizosphere isolates than for clinical ones.

\section{Synthesis of siderophores}

The four B. cepacia strains of clinical and rhizosphere origin appeared to synthesize Fe(III)-chelator(s) as shown by a strong positive reaction in the assay of Schwyn \& Neilands (1987). Culture supernatants of the $B$. cepacia strains grown for $48 \mathrm{~h}$ in Chelex-100-treated DCAA or succinate mineral medium were tested for the presence of catechol- and hydroxamate-type siderophores. Strains PHP7, TVV75, 7/25 and 9/27 did not release catechollike compounds, but produced a Fe(III)-repressible, hydroxamate-like molecule, the level of which approached $210 \mu \mathrm{M}, 156 \mu \mathrm{M}, 220 \mu \mathrm{M}$ and $240 \mu \mathrm{M}$, respectively. The addition of $100 \mu \mathrm{M} \mathrm{FeCl}$ to the $\mathrm{Fe}(\mathrm{III})$-poor media strongly repressed hydroxamate synthesis. TLC analysis of acidified ethyl acetate extracts from culture supernatants in DCAA of strains PHP7, TVV75, 7/25 and 9/27 showed that, similarly to the $P$. aeruginosa PAO1 control, clinical B. cepacia isolates produced pyochelin and its biosynthetic precursor salicylic acid, in response to conditions of limiting $\mathrm{Fe}$ (III) (Fig. 2). In contrast, rhizosphere isolates were unable to synthesize either pyochelin or salicylate. Pyochelin $\left(R_{F}\right.$ values approximately 0.35 and 0.40 ), migrated as two distinct bands (Visca et al., 1993), displayed grey-green fluorescence emission under UV light, turned brown-red when sprayed with acidic $\mathrm{FeCl}_{3}$, and reacted with the ammoniacal silver nitrate reagent for thiazolidine groups yielding black silver mercaptide salts. Salicylic acid $\left(R_{F}\right.$ approximately $0 \cdot 70$, in agreement with Visca et al., 1993) had a bluefluorescence under UV light and turned violet after spraying with $\mathrm{FeCl}_{3}$, but did not react with ammoniacal silver nitrate reagent. Salicylate and, to a lesser extent, pyochelin production were repressed in succinate mineral medium, as already reported for pyochelin synthesis by $P$. aeruginosa PAO1 (Cox \& Graham, 1979). The $R_{F}$ value of the hydroxamate-positive compound in the system used was $0 \cdot 18-0 \cdot 20$ as determined by fractionation of the silica gel and analysis in the Csàky assay (1948) of the methanoleluted compound. (a)

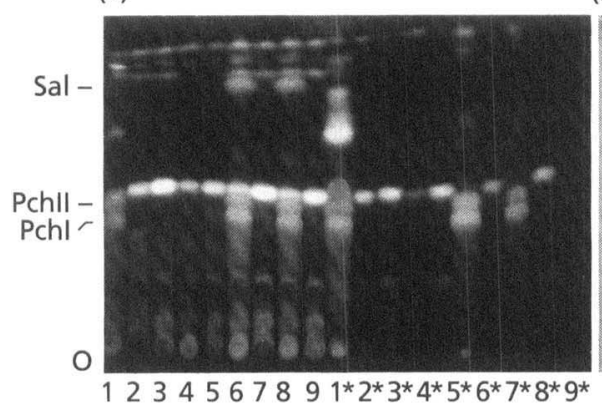

(b)

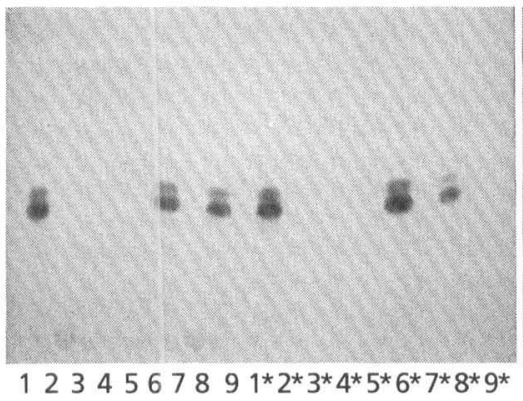

(c)

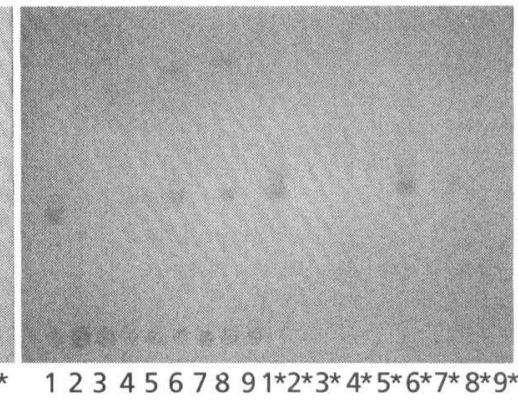

Fig. 2. Thin-layer chromatograms of acidified ethyl acetate and chloroform extracts from cultures of $P$. aeruginosa $P A O 1$ and $B$. cepacia strains grown in Fe(III)-deficient and $\mathrm{Fe}$ (III)-rich media. In Fe(III)-rich conditions $\mathrm{FeCl}_{3}$ was added to DCAA and succinate medium at a final concentration of $100 \mu \mathrm{M}$ (see Methods). Lanes: 1 and 1*, P. aeruginosa PAO1 in Fe(III)poor DCAA and succinate medium, respectively; 2 and $2^{*}, B$. cepacia PHP7 in Fe(III)-poor DCAA and succinate medium, respectively; 3 and $3^{\star}, B$. cepacia PHP7 in Fe(III)-rich CAA and succinate medium, respectively; 4 and $4^{\star}, B$. cepacia TVV75 in Fe(III)-poor DCAA and succinate medium, respectively; 5 and $5^{*}, B$. cepacia TVV75 in Fe(III)-rich CAA and succinate medium, respectively; 6 and $6 *, B$. cepacia $7 / 25$ in Fe(III)-poor DCAA and succinate medium, respectively; 7 and $7 *, B$. cepacia $7 / 25$ in $\mathrm{Fe}(\mathrm{III})$-rich CAA and succinate medium, respectively; 8 and $8 *$, B. cepacia $9 / 27$ in Fe(III)-poor DCAA and succinate medium, respectively; 9 and $9 *$, B. cepacia $9 / 27$ in Fe(III)-rich CAA and succinate medium, respectively. (a) Chromatograms were visualized by exposure to UV light; (b) chromatograms developed by spraying with the ammoniacal silver nitrate reagent for thiazolidine groups; (c) chromatograms developed by spraying with $0.1 \mathrm{M} \mathrm{FeCl}_{3}$ in $0.1 \mathrm{M} \mathrm{HCl}$. Abbreviations: O, origin of migration; Pchl and Pchll, two forms of pyochelin; Sal, salicylate. 


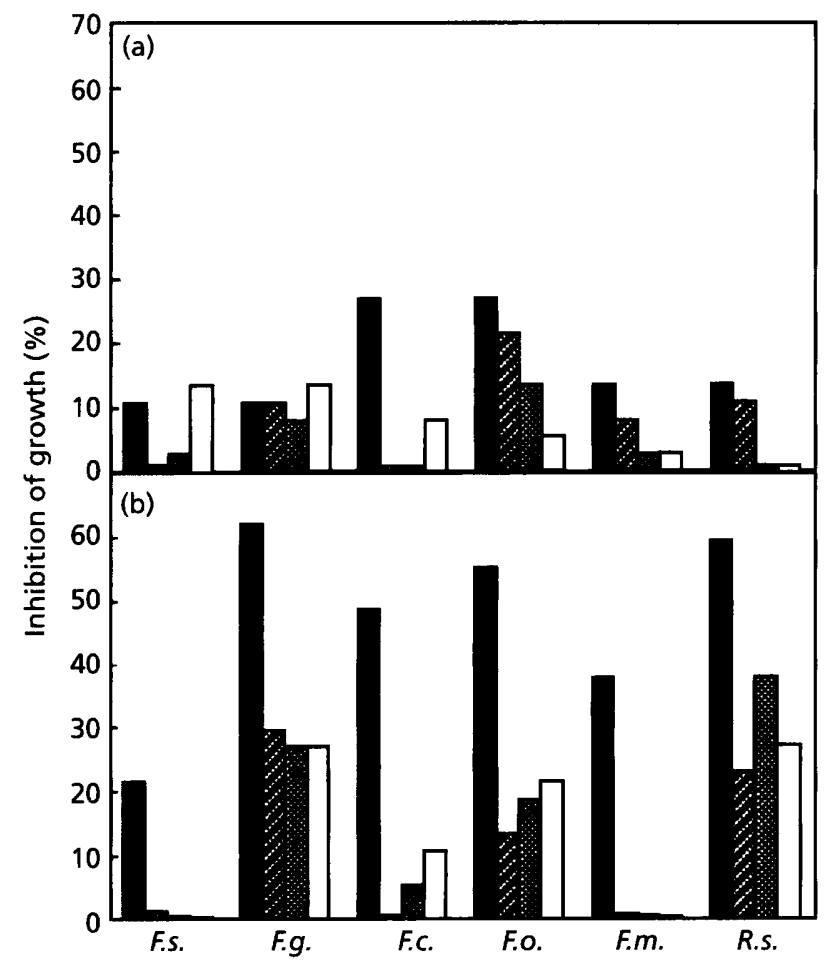

Fig. 3. Antagonistic activity of $B$. cepacia strains against fungal phytopathogens on PDA (a) and KB (b) media. Inhibition by

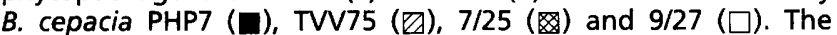
percentage inhibition of the growth of plant-pathogenic fungi was calculated according to Whipps (1987). F.s., Fusarium solani; F.g., F. graminearum; F.c., F. culmorum; F.o., F. oxysporum; F.m., F. moniliforme; R.s., Rhizoctonia solani.

Table 1. Adherence of $B$. cepacia strains to cucumber roots

Each value represents mean $\pm \mathrm{SD}(n=3)$

\begin{tabular}{|llcc|}
\hline Strain & Origin & $\begin{array}{c}\text { No. of cells } \\
\text { per seedling } \\
\text { initially } \\
\left(\mathbf{1 0}^{-6} \times\right. \\
\text { c.f.u. } \pm \text { SD) }\end{array}$ & $\begin{array}{c}\text { No. of cells } \\
\text { per fresh } \\
\text { weight of root* } \\
\left(\mathbf{1 0}^{-\mathbf{7}} \times\right. \\
\left.\text { c.f.u. } \mathbf{g}^{-1} \pm \mathbf{S D}\right)\end{array}$ \\
\hline PHP7 & Rhizosphere & $1 \cdot 7 \pm 0 \cdot 4$ & $1 \cdot 4 \pm 0 \cdot 8$ \\
TVV75 & Rhizosphere & $5 \cdot 8 \pm 0 \cdot 7$ & $2 \cdot 3 \pm 0 \cdot 7$ \\
$7 / 25$ & Human & $1 \cdot 8 \pm 0 \cdot 4$ & $2 \cdot 1 \pm 0 \cdot 6$ \\
$9 / 27$ & Human & $1.5 \pm 0 \cdot 3$ & $3 \cdot 1 \pm 0 \cdot 7$ \\
\hline
\end{tabular}

* No bacteria were detected inside the cucumber roots after $\mathrm{Ca}(\mathrm{ClO})_{2}$ surface sterilization.

\section{Production of IAA, HCN and protease(s)}

Differentiation of strains by production of IAA revealed production in the rhizosphere isolates only; the level of IAA in late-stationary-phase cultures approached 0.6 and $0.4 \mu \mathrm{g} \mathrm{ml}^{-1}$ for strains PHP7 and TVV75, respectively. None of $B$. cepacia strains produced $\mathrm{HCN}$, whereas the control strain $P$. aeruginosa PAO1 did. Moreover, no proteolytic activity was detected in culture supernatants of rhizosphere isolates PHP7 and TVV75; conversely, clinical strains $7 / 25$ and $9 / 27$ showed relatively high proteolytic activity. The level of protease(s) in culture supernatants of strains $7 / 25$ and $9 / 27$ grown in SM9 were 0.69 and $0.39 \mathrm{U} \mathrm{ml}^{-1}$, respectively.

\section{Nitrogenase activity}

Under standard conditions the rhizosphere isolates PHP7 and TVV75 showed a $\mathrm{N}_{2}$-fixing activity of 620 and $715 \mathrm{nmol} \mathrm{C}_{2} \mathrm{H}_{4} \mathrm{~h}^{-1}$ produced per flask when grown in suspension culture under $0 \cdot 1 \% \mathrm{O}_{2}, \mathrm{C}_{2} \mathrm{H}_{2}$ reduction was not shown by clinical strains $7 / 25$ and $9 / 27$ under the same experimental conditions.

\section{Suppression of fungal pathogens}

The antagonistic activity of $B$. cepacia PHP7, TVV75, $7 / 25$ and $9 / 27$ against six fungal phytopathogens was tested in a plate assay using KB and PDA media. The results shown in Fig. 3 indicate that all B. cepacia strains were able to restrict the growth of several fungal pathogens on both $\mathrm{KB}$ and PDA, although to differing degrees. The inhibition was more evident on $\mathrm{KB}$, whereas on PDA the effect was strongly reduced. Only strain PHP7 inhibited all six of the fungi tested and exerted a generally higher antagonistic effect in comparison with the other $B$. cepacia strains. The most sensitive fungi were $F$.graminearum, R. solani, F. oxysporum, and F. culmorum on $\mathrm{KB}$, and $F$. culmorum and $F$. graminearum on PDA.

\section{Adherence to human uroepithelial cells}

Adherence to uroepithelial cells was demonstrated for the clinical strains $9 / 27$ and $7 / 25$ only. Strain $7 / 25$ appeared to be more adhesive than strain $9 / 27$ (approximately 50 and 30 attached bacteria per epithelial cell, respectively). Cell-associated bacteria were not observed with rhizosphere isolates of B. cepacia.

\section{Adherence to $C$. sativus roots}

Table 1 shows comparative data on the ability of B. cepacia strains to adhere to $C$. sativus roots under sterile conditions. Bacterial adherence was assessed by evaluating the bacterial population associated with the roots $7 \mathrm{~d}$ after the inoculation. It was observed that most of the rootassociated bacteria were removed during the first wash (approximately $10^{6}$ c.f.u. $\mathrm{ml}^{-1}$ ), whereas in the second through to the fifth washes approximately $10^{4}$ and $10^{3}$ c.f.u. $\mathrm{ml}^{-1}$ were removed, respectively (data not shown). Thus, the first wash was effective in removing bacteria from the roots and multiple wash steps did not cause a significant decrease in the number of attached organisms. On this basis we assumed that after five washes the number of bacteria present on the root corresponded to the number of bacteria which were irreversibly associated with the root. Under these experimental conditions all four B. cepacia strains became 
Table 2. Effect of $B$. cepacia strains on root dry weight: of $C$. sativus

In each case inoculation was with approx. $10^{6}$ c.f.u. B. cepacia. $V$ alues are the means of 16 replicates. Values designated with the same letter $(\mathrm{a}, \mathrm{b}$ or $\mathrm{c})$ are not significantly different $(P=0.05)$ according to Duncan's Multiple-Range Test.

\begin{tabular}{|lc|}
\hline Strain & Root dry wt (g) \\
\hline None (contiol) & $0.35 \mathrm{c}$ \\
PHP7 & $0.51 \mathrm{a}$ \\
TVV75 & $0.44 \mathrm{~b}$ \\
$7 / 25$ & $0.35 \mathrm{c}$ \\
$9 / 27$ & $0.37 \mathrm{c}$ \\
\hline
\end{tabular}

irreversibly attached to the roots, reaching values of approximately $10^{7}$ c.f.u. $\mathrm{g}^{-1}$ fresh weight of root. Furthermore, bacteria were not detected inside the cucumber roots as deduced from plate counts of viable cells obtained from an homogenate of $\mathrm{Ca}(\mathrm{ClO})_{2}$ surface-sterilized roots.

\section{Greenhouse studies}

Table 2 shows that inoculation of $C$. sativus seedlings with rhizosphere isolates PHP7 and TVV75 results in significantly higher dry weight values of plant roots by comparison with clinical strains $7 / 25$ and $9 / 27$, and with the uninoculated control $(P=0 \cdot 05)$. B. cepacia PHP7 and TVV75 exerted a positive effect on root dry weight only, as they did not cause any significant change in shoot dry weight (data not shown). Under identical conditions $B$. cepacia strains of clinical origin $(7 / 25$ and $9 / 27)$ did not cause any apparent change in root and shoot dry weight, as compared with the uninoculated controls.

\section{DISCUSSION}

In agriculture, application of plant-growth-promoting rhizobacteria (PGPR) is desiderable to improve crop production and to decrease utilization of chemical pesticides (de Freitas \& Germida, 1991; Kloepper et al., 1988; Suslow \& Schroth, 1982). The widespread use of PGPR in field experiments has been hampered by the possibility that massive introduction of exogenous micro-organisms in fields may be a risk factor for the balance of the ecosystem and for animal and human health. Thus, when a potentially pathogenic species has to be tested for plantgrowth-promoting (PGP) activity in field experiments, any environmental and health risk must be ruled out. Therefore, investigations designed to compare rhizosphere and clinical isolates of B. cepacia for some relevant virulence characteristics (e.g., adhesiveness to human uroepithelial cells, synthesis of protease(s), and siderophores) and for some traits associated with known PGP activity (e.g., root colonization, synthesis of siderophores, antibiosis against fungal phytopathogens, $\mathrm{N}_{2}$-fixation, and production of IAA and HCN) were carried out.

B. cepacia is recognized as one of the most nutritionally versatile species among Pseudomonadaceae (Stanier $e t$ al., 1966; Palleroni \& Holmes, 1981; Yabuuchi et al., 1992). Initially the ability of B. cepacia strains to grow on different carbon sources normally present in root exudates was explored. These organic substances are released by the plant roots and used as nutritional sources for rootcolonizing microbial populations (Rovira, 1956). The results obtained confirm the ability of $B$. cepacia to multiply using a wide range of organic compounds and indicate that rhizosphere and clinical strains differed for one biochemical trait only (L-lysine utilization). It was also observed that the optimal growth temperature of rhizosphere isolates was in the range $37-42^{\circ} \mathrm{C}$, rather than $25-28^{\circ} \mathrm{C}$ which is the generally accepted growth temperature of soil bacteria. In contrast, clinical strains grew as well at high temperatures, but at lower temperatures their growth rates were significantly lower than those of rhizosphere isolates. This indicates that rhizosphere strains are better adapted to grow at low temperatures than clinical strains, which preferentially develop at body temperature. We also observed differences in the levels of extracellular protease(s) released by the strains studied. Only clinical strains showed proteolytic activity, in agreement with the role proposed for this extracellular enzyme(s) in the pathogenicity mechanism towards the human host (Janda \& Bottone, 1981).

It is now recognized that PGPR may benefit plant growth by providing nutrients and growth factors or by producing antibiotics, siderophores, and cyanide, which may inhibit pathogenic fungi and bacteria (Davidson, 1988). Phytohormone-like substances have been reported in fluorescent pseudomonads (Kloepper $e$ t al., 1989), but up to now no study has been published on production of plant hormones by B. cepacia. Results show that rhizosphere isolates are capable of synthesizing detectable amounts of IAA, while clinical isolates do not. The behaviour of rhizosphere and clinical B. cepacia strains examined in greenhouse studies clearly shows that rhizosphere isolates exert growth promotion of $C$. sativus roots independently of native root zone microflora; the clinical strains, in contrast, did not have any effect on $C$. sativus growth. In addition, nitrogen fixation allowed a differentiation between rhizosphere and clinical isolates of $B$. cepacia. The nitrogen fixing capability was observed for rhizosphere isolates only.

The ability of B. cepacia to inhibit the in vitro growth of several fungal phytopathogens was investigated. Differences in the level of anatagonism shown by the rhizosphere isolate PHP7 with respect to the other B. cepacia strains were observed. The antagonistic activity was affected by the medium composition, as it was higher on $\mathrm{KB}$ rather than PDA plates. It is generally assumed that the inhibition of fungal pathogens on PDA, being a $\mathrm{C}-, \mathrm{N}$ and $\mathrm{Fe}(\mathrm{III})$-rich medium, may be due to the production of antibiotic-like substances, and on $\mathrm{KB}$, an $\mathrm{Fe}$ (III)-deficient medium, the inhibition may occur by production of siderophores in addition to antibiotics (Hebbar et al., 1991). Since B. cepacia strains displayed higher inhibition of fungal growth in $\mathrm{Fe}$ (III)-poor medium, it can be hypothesized that siderophores could be involved in the 
antagonistic response. It is known that to counter the effect of $\mathrm{Fe}(\mathrm{III})$ limitation in the environment or within the mammalian host tissue, most micro-organisms have developed high-affinity systems for $\mathrm{Fe}(\mathrm{III})$ uptake, consisting of low-molecular-mass chelators, called siderophores, and their cognate membrane receptors (Cox, 1989). It has been established that release of siderophores may be partly responsible for enhanced plant growth (Kloepper et al., 1980), biocontrol (Leong, 1986) and morbidity and mortality in animal infections (Sokol, 1986; Sokol \& Woods, 1988). Clinical isolates of B. cepacia have been reported to produce pyochelin (Sokol, 1986), a salicyl-derived thiazo-compound, chemically unrelated to pyoverdins and pseudobactins, previously described in the fluorescent pseudomonads (Abdallah, 1991). Pyochelin has been shown to be a potent siderophore for clinical isolates of B. cepacia, and a correlation was found between its production and the severity of infection in cystic fibrosis patients (Sokol, 1986). We found that the clinical isolates of $B$. cepacia, $7 / 25$ and $9 / 27$, synthesize pyochelin, while the rhizosphere isolates PHP7 and TVV75 do not. In addition to pyochelin, clinical isolates of B. cepacia released detectable amounts of salicylic acid, the biosynthetic precursor of pyochelin. This molecule, formerly termed azurechelin (Sokol et al., 1992), has been shown to function as a siderophore in B. cepacia and fluorescent pseudomonads (Visca et al., 1993). Salicylic acid is a plant hormone known to exert a variety of positive functional effects on plants, e.g. induction of systemic resistance against pathogen attack (Enyedi $e t$ al., 1992; Raskin, 1992), so that it appears quite surprising that production of such a molecule was characteristic of clinical, rather than rhizosphere isolates. Moreover, both clinical and thizosphere isolates synthesize a hydroxamatelike compound which displays a strong reactivity in the Schwyn \& Neilands (1987) assay for siderophores. TLC analysis did not allow identification of this compound as cepabactin (Meyer et al., 1989) as had been previously described for B. cepacia. It will be of interest to investigate whether the hydroxamate-like compound can be related to the new ornibactin family of siderophores from a nonfluorescent Pseudomonas strain which resemble pyoverdins in their peptide structure, but lack the chromophore moiety (Stephan et al., 1993). The existence of additional $\mathrm{Fe}(\mathrm{III})$-transport systems in the pyochelin-producing clinical isolates of $B$. cepacia could be an advantage for human pathogenicity.

Another characteristic to be considered was the adhesion to uroepithelial cells, as the attachment of bacteria to the mucosal epithelia represents an essential step in the colonization of the host (Prince, 1992). Adhesiveness was demonstrated for clinical strains $7 / 25$ and $9 / 27$, while rhizosphere isolates were unable to adhere to uroepithelial cells. Thus, rhizosphere isolates appear to lack specific structures involved in the adhesion to human mucosa. In contrast, the screening of $B$. cepacia strains for the ability to attach to plant root surfaces indicated that all the strains adhere to cucumber roots in the absence of competition, but are unable to penetrate inside the roots. It should be stressed that the root-adherence assay was performed in vitro under sterile conditions, i.e. in the absence of competing microflora, and therefore does not predict whether the bacterium will actually colonize a root surface, but only determines the potential ability to adhere and/or proliferate at the rhizoplane (James et al., 1985). Our results suggest that the adherence of $B$. cepacia strains to cucumber roots does not involve specific recognition events and that the $B$. cepacia isolates probably share similar surface properties which do not allow the discrimination between thizosphere and clinical bacteria for their root adhesion ability. Thus, while clear differences between rhizosphere and clinical isolates are evident in the adhesion test to the human epithelium, no distinction can be made between the two groups when the target is the root surface.

Differences between human- and plant-pathogenic B. cepacia strains have been reported previously (Gonzalez $\&$ Vidaver, 1979); these were based on bacteriocin production, maceration of onion slices, pectolytic activity, and plasmid profile. However, the extent of variation of phenotypic traits between PGP and clinical B. cepacia isolates was still not clear. In the present study, relevant characteristics related to virulence and PGP activity were analysed in clinical and rhizosphere isolates of B. cepacia. It has been observed that $B$. cepacia strains of clinical origin lack factors involved in PGP activity as compared to rhizosphere isolates. Conversely, the rhizosphere isolates appear to have reduced virulence potential by comparison with PGP isolates. Such an evolutionary divergence probably results from the selection exerted by extremely diverse ecological niches on colonizing strains and leads us to hypothesize that the PGP B. cepacia isolates may have a very limited capacity for acting as pathogens. However, due to the limited number of strains examined to date, further work is still required to determine whether this divergent trend is universal within the species.

\section{ACKNOWLEDGEMENTS}

Dr M. Vittoria Carusi was supported by a grant from the Progetto Formazione Biotecnologia avanzata, Decreto B MURST 29/10/91. We are grateful to T. Heulin and Tran Van Van for the generous gifts of B. cepacia strains PHP7 and TVV75, respectively.

\section{REFERENCES}

Abdallah, M. A. (1991). Pyoverdins and pseudobactins. In $C R C$ Handbook of Microbial Iron Chelates, pp. 139-153. Edited by G. Winkelmann. Boca Raton, Ann Arbor, Boston, London: CRC Press.

Arnow, L. E. (1937). Colorimetric determination of the components of 3,4-dihydroxyphenylalanine-tyrosine mixtures. J Biol Chem 228, 531-537.

Burkholder, W. H. (1950). Sour skin, a bacterial rot of onion bulbs. Pbytopatbology 40, 115-117.

Carson, L. A., Favero, M. S., Bond, W. W. \& Petersen, N. J. (1973). Morphological, biochemical, and growth characteristics of Pseudomonas cepacia from distilled water. Appl Microbiol 25, 476-483.

Castric, K. F. \& Castric, P. A. (1983). Method for rapid detection of cyanogenic bacteria. Appl Environ Microbiol 45, 701-702. 
Cox, C. D. (1989). Importance of iron in bacterial virulence. In Metal Ions and Bacteria, pp. 207-246. Edited by T. J. Beveridge \& R. J. Doyle. New York: John Wiley \& Sons.

Cox, C. D. \& Graham, R. (1979). Isolation of an iron-binding compound from Pseudomonas aeruginosa. J Bacteriol 137, 357-364.

Craven, E. E., Moody, B., Connolly, M. G., Kollisch, N. R., Stottmeier, K. D. \& McCabe, W. R. (1981). Pseudobacteremia caused by povidone-iodine solution contaminated with Pseudomonas cepacia. N Engl J Med 305, 621-623.

Csàky, T. Z. (1948). On the estimation of bound hydroxylamine in biological materials. Acta Chem Scand 2, 450-454.

Davidson, J. (1988). Plant beneficial bacteria. Biotechnology 6, 282-286.

Ehmann, A. (1977). The Van Urk-Salkowski reagent - a sensitive and specific chromogenic reagent for silica gel thin-layer chromatographic detection and identification of indole derivatives. $J$ Chromatogr 132, 267-276.

Enyedi, A. J., Yalpani, N., Silverman, P. \& Raskin, I. (1992). Signal molecules in systemic plant resistance to pathogens and pests. Cell 70, 879-886.

Feigl, F. \& Anger, V. (1966). Replacement of benzidine by copper ethylacetoacetate and tetrabase as spot-test reagent for hydrogen cyanide and cyanogen. Analyst 91, 282-284.

Folsom, B. R., Chapman, P. J. \& Pritchard, P. H. (1990). Phenol and trichloroethylene degradation by Pseudomonas cepacia G4: kinetics and interactions between substrates. Appl Environ Microbiol 56, 1279-1285.

Forni, C., Riov, J., Grilli Caiola, M. \& Tel-Or, E. (1992). Indole-3acetic acid (IAA) production by Artbrobacter species isolated from Azolla. J Gen Microbiol 138, 377-381.

de Freitas, J. R. \& Germida, J. J. (1991). Pseudomonas cepacia and Pseudomonas putida as winter wheat inoculants for biocontrol of Rbizoctonia solani. Can J Microbiol 37, 780-784.

Gilardi, G. L. (1971). Antimicrobial susceptibility as a diagnostic aid in the identification of nonfermenting Gram-negative bacteria. Appl Microbiol 22, 821-823.

Gilardi, G. L. (1983). Pseudomonas cepacia: culture and laboratory identification. Lab Manage 21, 29-32.

Goldmann, D. A. \& Klinger, J. D. (1986). Pseudomonas cepacia biology, mechanisms of virulence, epidemiology. J Pediatr 108. 806-812.

Gonzalez, C. F. \& Vidaver, A. K. (1979). Bacteriocin, plasmid and pectolytic diversity in Pseudomonas cepacia of clinical and plant origin. J Gen Microbiol 110, 161-170.

Guterman, S. K. (1973). Colicin B : mode of action and inhibition by enterochelin. J Bacteriol 114, 1217-1224.

Hardy, R. W. F., Burns, R. C. \& Holsten, R. D. (1973). Application of the acetylene-ethylene assay for measurements of nitrogert fixation. Soil Biol Biochem 5, 47-81.

Hebbar, P., Berge, O., Heulin, T. \& Singh, S. P. (1991). Bacterial antagonists of Sunflower (Helianthus annus L.) fungal pathogens. Plant Soil 133, 131-140.

Hebbar, K. P., Davey, A. G. \& Dart, P. J. (1992a). Rhizobacteria of maize antagonistic to Fusarium moniliforme, a soil-borne fungal pathogen : isolation and identification. Soil Biol Biochem 24, 979-987.

Hebbar, K. P., Davey, A. G., Merrin, J. \& Dart, P. J. (1992b). Rhizobacteria of maize antagonistic to Fusarium moniliforme, soilborne fungal pathogen: colonization of rhizosphere and roots. Soil Biol Biochem 24, 989-997.

Hebbar, K. P., Davey, A. G., Merrin, J., McLoughlin, T. J. \& Dart, P. J. (1992c). Pseudomonas cepacia, a potential suppressor of maize soil-borne diseases - seed inoculation and maize root colonization. Soil Biol Biochem 24, 999-1007.

Homma, Y., Chikuo, Y. \& Ogoshi, A. (1990). Mode of suppression of sugar beet damping-off caused by Rhizoctonia solani by seed bacterization with Pseudomonas cepacia. In Plant Growth-Promoting Rbizobacteria - Progress and Prospects, pp. 115-118. Edited by C. Keel, B. Koller \& G. Défago. IOBC/WPRS Bulletin 1991/XIV/8.

Isles, A., Maclusky, I., Corey, M., Gold, R., Prober, C., Fleming, P. \& Levison, H. (1984). Pseudomonas cepacia infection in cystic fibrosis: an emerging problem. J Pediatr 104, 206-210.

James, D. W., Suslow, T. V. \& Steinback, K. E. (1985). Relationship between rapid, firm adhesion and long-term colonization of roots by bacteria. Appl Environ Microbiol 50, 392-397.

Janda, J. M. \& Bottone, E. J. (1981). Pseudomonas aeruginosa enzyme profiling: prediction of potential invasiveness and use as an epidemiological tool. J Clin Microbiol 14, 55-60.

Kilbane, J. J., Chatterjee, D. K. \& Chakrabarty, A. M. (1983). Detoxification of 2,4,5-trichlorophenoxyacetic acid from contaminated soil by Pseudomonas cepacia. Appl Environ Microbiol 45, $1697-1700$.

KIng, E. O., Ward, M. K. \& Raney, D. E. (1954). Two simple media for demonstration of pyocyanin and fluorescein. J Lab Clin Med 44, 301-307.

Kloepper, J. W., Leong, J., Tientze, M. \& Schroth, M. N. (1980). Enhanced plant growth by siderophores produced by plant growth promoting rhizobacteria. Nature 286, 885-886.

Kloepper, J. W., Lifshitz, R. \& Schroth, M. N. (1988). Pseudomonas inoculants to benefit plant production. ISI Atlas of Science: Animal and Plant Sciences, pp. 60-64. Philadelphia: Institute for Public Information.

Kloepper, J. W., Lifshitz, R. \& Zablotowicz, R. M. (1989). Free living bacterial inocula for enhancing crop productivity. Trends Biotechnol 7, 39-44.

Lennon, E. \& DeCicco, B. T. (1991). Plasmids of Pseudomonas cepacia strains of diverse origins. Appl Environ Microbiol 57, 2345-2350.

Leong, J. (1986). Siderophores: their biochemistry and possible role in the biocontrol of plant pathogens. Annu Rev Phytopathol 24, 187-209.

Lifshitz, R., Kloepper, J. W., Scher, F. M., Tipping, E. M. \& Laliberté, M. (1986). Nitrogen-fixing Pseudomonads isolated from roots of plants grown in the Canadian high arctic. Appl Environ Microbiol 51, 251-255.

McKevitt, A. I. \& Woods, D. E. (1984). Characterization of B. cepacia isolates from patients with cystic fibrosis. J Clin Microbiol 19, 291-293.

McLoughlin, T. J., Quinn, J. P., Bettermann, A. \& Bookland, R. (1992). Pseudomonas cepacia suppression of Sunflower wilt fungus and role of antifungal compounds in controlling the disease. Appl Environ Microbiol 58, 1760-1763.

Martone, W. J., Tablan, O. C. \& Jarvis, W. R. (1987). The epidemiology of nosocomial epidemic Pseudomonas cepacia infections. Eur J Epidemiol 3, 222-232.

Meyer, J. M., Hohnadel, D. \& Hallé, F. (1989). Cepabactin from Pseudomonas cepacia, a new type of siderophore. J Gen Microbiol 135, 1479-1487.

Mitchell, J. W. \& Livingstone, G. A. (1968). Methods of studying plant hormones and growth regulating substances. In Agriculture Handbook, p. 336. US Department of Agriculture.

Palleroni, N. J. (1984). Pseudomonadaceae. In Bergey's Manual of Systematic Bacteriology, vol. 1, pp. 141-149. Edited by N. R. Krieg \& J. G. Holt. Baltimore: Williams \& Wilkins. 
Palleroni, N. J. \& Holmes, B. (1981). Pseudomonas cepacia sp. nov., nom. rev. Int J Syst Bacteriol 31, 479-481.

Prince, A. (1992). Adhesins and receptors of Pseudomonas aeruginosa associated with infection of the respiratory tract. Microb Pathog 13, 251-260.

Raskin, I. (1992). Role of salicylic acid in plants. Annu Rev Plant Mol Biol 43, 439-463.

Rovira, A. D. (1956). Plant root excretions in relation to the rhizosphere effect. II. A study of the properties of root exudate and its effect on the growth of micro-organisms isolated from the rhizosphere and control soil. Plant Soil 7, 195-208.

Rovira, A. D. (1965). Plant root exudates and their influence upon soil micro-organisms. In Ecology of Soil-borne Plant PatbogensPrelude to Biological Control, p. 170. Edited by K. F. Baker \& W. C. Snyder. University of California.

Sagee, O., Maoz, A., Mertens, R., Goren, R. \& Riov, J. (1986). Comparison of different enzyme immunoassays for measuring indole-3-acetic acid in vegetative citrus tissue. Pbysiol Plant 68, 265-270.

Schwyn, B. \& Neilands, J. B. (1987). Universal chemical assay for the detection and determination of siderophores. Anal Biochem 160, 47-56.

Sokol, P. A. (1986). Production and utilization of pyochelin by clinical isolates of Pseudomonas cepacia. J Clin Microbiol 23, 560-562.

Sokol, P. A. \& Woods, D. E. (1988). Effect of pyochelin on Pseudomonas cepacia respiratory infections. Microb Pathog 5, 197-205.

Sokol, P. A., Lewis, C. J. \& Dennis, J. J. (1992). Isolation of a novel siderophore from Pseudomonas cepacia. J Med Microbiol 36, 184-189.

Stanier, R. Y., Palleroni, N. J. \& Doudoroff, M. (1966). The aerobic pseudomonads: a taxonomic study. J Gen Microbiol 43, 159-271.

Stephan, H., Freund, S., Meyer, J. M., Winkelmann, G. \& Jung, G. (1993). Structure elucidation of the gallium-ornibactin complex by 2D-NMR spectroscopy. Liebigs Ann Chem 1, 43-48.
Suslow, T. V. \& Schroth, M. N. (1982). Rhizobacteria on sugar beets: effect of seed application and root colonization on yield. Pbytopathology 72, 199-206.

Thomassen, M. J., Demko, C. A., Klinger, J. D. \& Stern, R. C. (1985). Pseudomonas cepacia colonization among patients with cystic fibrosis. A new opportunist. Am Rev Respir Dis 113, 791-796.

Tomarelli, R. M., Charney, J. \& Harding, M. L. (1949). The use of azoalbumin as a substrate in the colorimetric determination of peptic and tryptic activity. J Lab Clin Med 34, 428-433.

Visca, P., Chiarini, F., Mansi, A., Vetriani, C., Serino, L. \& Orsi, N. (1992a). Virulence determinants in Pseudomonas aeruginosa strains from urinary tract infections. Epidemiol Infect 108, 323-336.

Visca, P., Colotti, G., Serino, L., Verzili, D., Orsi, N. \& Chiancone, E. (1992b). Metal regulation of siderophores synthesis in Pseudomonas aeruginosa and functional effects of siderophore-metal complexes. Appl Environ Microbiol 58, 2886-2893.

Visca, P., Serino, L. \& Orsi, N. (1992c). Isolation and characterization of Pseudomonas aeruginosa mutants blocked in the synthesis of pyoverdin. J Bacteriol 174, 5727-5731.

Visca, P., Ciervo, A., Sanfilippo, V. \& Orsi, N. (1993). Iron-regulated salicylate synthesis by Pseudomonas spp. J Gen Microbiol 139, 1995-2001.

Whipps, J. M. (1987). Effect of media on growth and interactions between a range of soil-borne glasshouse pathogens and antagonistic fungi. New Pbytol 107, 127-142.

Yabuuchi, E., Kosako, Y., Oyaizu, H., Yano, I., Hotta, H., Hashimoto, Y., Ezaki, T. \& Arakawa, M. (1992). Proposal of Burkholderia gen. nov. and transfer of seven species of the genus Pseudomonas homology group II to the new genus, with the type species Burkbolderia cepacia (Palleroni and Holmes 1981) comb. nov. Microbiol Immunol 36, 1251-1275.

Received 29 July 1993; revised 12 November 1993; accepted 26 November 1993. 